10-1-2002

\title{
H2O-D2O Condensation in A Supersonic Nozzle
}

\author{
Christopher H. Heath \\ Worcester Polytechnic Institute \\ Kiril A. Streletzky \\ Cleveland State University, K.STRELETZKY@csuohio.edu \\ Barbara E. Wyslouzil \\ Worcester Polytechnic Institute, barbaraw@wpi.edu \\ Judith Woelk \\ University of Cologne \\ Reinhard Strey \\ University of Cologne
}

Follow this and additional works at: https://engagedscholarship.csuohio.edu/sciphysics_facpub

Part of the Physics Commons

How does access to this work benefit you? Let us know!

Publisher's Statement

(C) 2002 American Institute of Physics.

\section{Repository Citation}

Heath, Christopher H.; Streletzky, Kiril A.; Wyslouzil, Barbara E.; Woelk, Judith; and Strey, Reinhard, "H2O-D2O Condensation in A Supersonic Nozzle" (2002). Physics Faculty Publications. 254.

https://engagedscholarship.csuohio.edu/sciphysics_facpub/254

This Article is brought to you for free and open access by the Physics Department at EngagedScholarship@CSU. It has been accepted for inclusion in Physics Faculty Publications by an authorized administrator of

EngagedScholarship@CSU. For more information, please contact library.es@csuohio.edu. 


\section{$\mathrm{H}_{2} \mathrm{O}-\mathrm{D}_{2} \mathrm{O}$ condensation in a supersonic nozzle}

Christopher H. Heath, Kiril Streletzky, and Barbara E. WyslouzilJudith Wölk and Reinhard Strey

Citation: 117, 6176 (2002); doi: 10.1063/1.1502644

View online: http://dx.doi.org/10.1063/1.1502644

View Table of Contents: http://aip.scitation.org/toc/jcp/117/13

Published by the American Institute of Physics

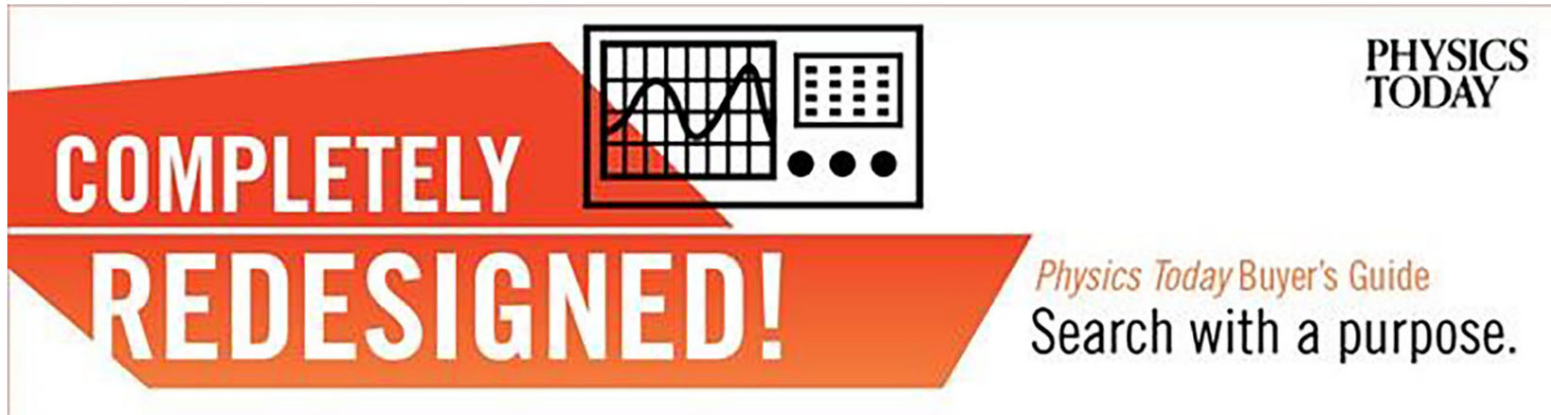




\title{
$\mathrm{H}_{2} \mathrm{O}-\mathrm{D}_{2} \mathrm{O}$ condensation in a supersonic nozzle
}

\author{
Christopher H. Heath, Kiril Streletzky, and Barbara E. Wyslouzila) \\ Department of Chemical Engineering, Worcester Polytechnic Institute, Worcester, Massachusetts 01609-2280
}

\author{
Judith Wölk and Reinhard Strey \\ Institut für Physikalische Chemie, Universität zu Köln, 50939 Köln, Germany
}

(Received 18 April 2002; accepted 2 July 2002)

\begin{abstract}
We examined the condensation of $\mathrm{H}_{2} \mathrm{O}, \mathrm{D}_{2} \mathrm{O}$, and four intermediate mixtures $(20,40,60$, and 80 $\mathrm{mol} \% \mathrm{D}_{2} \mathrm{O}$ ) in a supersonic nozzle. Because the physical and chemical properties of protonated and deuterated water are so similar, this system is ideal for studying the change in condensation behavior as a function of condensible composition. In our experiments dilute mixtures of condensible vapor in $\mathrm{N}_{2}$ are expanded from three different stagnation temperatures resulting in a broad range of onset temperatures $(190-238 \mathrm{~K})$ and pressures $(27-787 \mathrm{kPa})$. For a fixed stagnation temperature, the partial pressure required to maintain the onset of condensation at a given location or temperature in the nozzle is consistently higher for $\mathrm{H}_{2} \mathrm{O}$ than for $\mathrm{D}_{2} \mathrm{O}$. In contrast, the supersaturation at fixed onset temperature is usually higher for $\mathrm{D}_{2} \mathrm{O}$ than for $\mathrm{H}_{2} \mathrm{O}$ and this difference increases toward lower temperature. The partial pressure at onset for the intermediate mixtures varied linearly between the values observed for the pure components in this ideal system. (C) 2002 American Institute of Physics. [DOI: 10.1063/1.1502644]
\end{abstract}

\section{INTRODUCTION}

Water condensation occurs in many natural and industrial processes including cloud formation, power generation, and turbomechanical flows. One way to enhance our understanding of the behavior of this important substance is to conduct experiments using light water, $\mathrm{H}_{2} \mathrm{O}$, heavy water, $\mathrm{D}_{2} \mathrm{O}$, and their mixtures. The $\mathrm{H}_{2} \mathrm{O}-\mathrm{D}_{2} \mathrm{O}$ system is also ideal for studying binary condensation because the molecules are so similar. Pure $\mathrm{H}_{2} \mathrm{O}$ and $\mathrm{D}_{2} \mathrm{O}$ have comparable equilibrium vapor pressures, and the other important physical properties, in particular surface tension, do not differ greatly. Thus, unlike binary condensation in aqueous alcohol systems, ${ }^{1-3}$ surface enrichment effects should not be important.

Condensation studies in nozzles began indirectly with the development of high speed wind tunnels, where researchers found that heat addition from condensing water vapor altered the desired expansions. ${ }^{4}$ Thus, early nozzle condensation experiments focused primarily on water. Water often played a role in condensation experiments of other substances because the air used as a carrier gas frequently contained trace amounts of moisture. ${ }^{5,6}$ In nozzles, water condensation experiments range from those that start with pure steam $^{7,8}$ to those where the water is highly diluted in an inert carrier gas. ${ }^{2,9}$ The current experiments are in the latter category with a maximum water concentration of $3.5 \mathrm{~mol} \%$ water or $0.017 \mathrm{~kg}_{\mathrm{H}_{2} \mathrm{O}} / \mathrm{kg}_{\mathrm{N}_{2}}$. In addition to the onset measurements made in nozzles, water nucleation rates have been measured extensively using expansion cloud chambers, ${ }^{10-14}$ shock tubes, ${ }^{15,16}$ and the diffusion cloud chamber. ${ }^{17}$

In contrast to $\mathrm{H}_{2} \mathrm{O}$ there is only a limited data base avail-

\footnotetext{
a) Author to whom correspondence should be addressed; electronic mail: barbaraw@wpi.edu
}

able for the condensation of $\mathrm{D}_{2} \mathrm{O}$. The earliest work is that of Flood and Tronstad ${ }^{18}$ who measured the critical supersaturations for $\mathrm{D}_{2} \mathrm{O}$ condensation in an expansion cloud chamber in 1935. In 1977 Lee reported the condensation onset pressures and temperatures for both $\mathrm{H}_{2} \mathrm{O}$ and $\mathrm{D}_{2} \mathrm{O}$ in a shock tube. ${ }^{19}$ Given the scatter in his data, it is difficult to distinguish an effect due to deuteration. The most comprehensive nucleation rate measurements to date for $\mathrm{D}_{2} \mathrm{O}$ are those of Wölk and Strey. ${ }^{14}$ In an extensive set of nucleation pulse chamber experiments, they measured nucleation rates $J$ for $\mathrm{H}_{2} \mathrm{O}$ and $\mathrm{D}_{2} \mathrm{O}$ in the range $10^{6}<\mathrm{J} / \mathrm{cm}^{-3} \mathrm{~s}^{-1}<10^{9}$ for temperatures between 220 and $260 \mathrm{~K}$. They found that for a given condensible vapor pressure and temperature the nucleation rates of $\mathrm{D}_{2} \mathrm{O}$ were higher than those for $\mathrm{H}_{2} \mathrm{O}$, but that the data agreed within experimental error if the rates were compared at the same supersaturation and temperature. Our experiments complement the work of Wölk and Strey because peak nucleation rates in conventional nozzle experiments are about 8 orders of magnitude higher and onset temperatures are up to $30 \mathrm{~K}$ lower than those in the nucleation pulse chamber.

Finally, this work is also motivated by our ongoing small angle neutron scattering (SANS) experiments from aerosols. Nucleation in supersonic nozzles produces a high number density aerosol $\left(\sim 10^{12} \mathrm{~cm}^{-3}\right)$ of nanometer-size droplets. ${ }^{20-23}$ The small droplet size makes it difficult to uniquely characterize the aerosol size distribution using conventional optical techniques, and sampling the aerosol is difficult because the droplets evaporate as soon as the flow decelerates. When the droplets consist of molecules with a high neutron scattering length density, such as $\mathrm{D}_{2} \mathrm{O}$, then SANS experiments can quantitatively determine the properties of the aerosol. ${ }^{20,21,24}$ Although the two isotopic forms of water have similar physical properties, the presence or absence of 
an additional neutron in the nucleus of the hydrogen atom substantially changes the nuclear properties of the compound. Thus, light water aerosols produced in our nozzle have too weak a neutron scattering signal for aerosol-SANS experiments to give useful results. Studying the change in condensation phenomena as a function of mixture composition should make it possible to better account for effects of deuteration and therefore learn about the behavior of weakly scattering molecules by studying their strongly scattering counterparts.

Here we describe the results of our conventional $\mathrm{H}_{2} \mathrm{O}-\mathrm{D}_{2} \mathrm{O}$ condensation studies starting from a stagnation pressure $p_{0}$ of $59.6 \mathrm{kPa}$ and stagnation temperatures $T_{0}$ of $13.5,26.0$, and $35.0^{\circ} \mathrm{C}$. We report the onset data and discuss the general nature of the condensation processes for pure $\mathrm{H}_{2} \mathrm{O}$ and $\mathrm{D}_{2} \mathrm{O}$, and mixtures containing $20,40,60$, and 80 mol $\% \mathrm{D}_{2} \mathrm{O}$. In addition to providing a basis for planning the SANS experiments, ${ }^{22,23}$ this extensive data base is an invaluable resource for modeling unary and multicomponent droplet formation under extremes of temperature and supersaturation.

The paper is organized as follows. We first discuss minor changes made to the system before and during the $\mathrm{H}_{2} \mathrm{O}-\mathrm{D}_{2} \mathrm{O}$ condensation experiments. We then present and discuss the experimental results in the order that they were generated. Finally, we summarize the work and present our conclusions.

\section{EXPERIMENT}

Detailed descriptions of the experimental setup, procedures, and data reduction methods are available in a previous paper. ${ }^{2}$ Here, we briefly summarize the experimental technique and describe minor changes made to the system.

In our apparatus, a mixture of noncondensible gas and condensible vapor expands through a supersonic nozzle cooling at rates of up to $\sim 10^{6} \mathrm{~K} / \mathrm{s}$. Supersaturations as high as several hundred are reached in the nozzle before the vapor condenses via homogeneous nucleation and droplet growth. All experiments start at a fixed stagnation pressure and temperature, and the static pressure is measured along the length of the nozzle using a narrow diameter probe. Expansion of a pure carrier gas characterizes the area ratio of the nozzle. To determine the thermodynamic state of the flow in the presence of condensation, we integrate the diabatic flow equations using the measured area ratio and the condensing flow pressure profile as input. ${ }^{2} \mathrm{~A} 0.5 \mathrm{~K}$ difference between the temperature of the condensing flow and the temperature for an isentropic expansion of the same gas mixture defines the onset of condensation.

In these binary condensation experiments we fix the $\mathrm{H}_{2} \mathrm{O}: \mathrm{D}_{2} \mathrm{O}$ ratio in the gas phase, and then vary the partial pressure of the condensible vapor in the expanding gas to determine the relationship between onset pressure and temperature (the Wilson line). We then change the $\mathrm{H}_{2} \mathrm{O}: \mathrm{D}_{2} \mathrm{O}$ ratio and repeat the experiments to explore the effect of gas phase composition on the onset of condensation in this highly ideal system.

\section{A. Equipment changes}

All condensation experiments are performed from constant plenum pressure. The stagnation pressure $p_{0}$ differs slightly from the plenum pressure, however, because of several nonisentropic losses incurred between the plenum and the entrance to the nozzle. In the setup used for the $\mathrm{H}_{2} \mathrm{O}-n$-alcohol experiments, ${ }^{2}$ the greatest pressure drop was due to a mesh screen located between the flow straightener and the nozzle that supported the leading edge of the pressure probe. For these experiments, we replaced the mesh by four wires forming a diagonal cross pattern and reduced the pressure losses from 1.2 to $0.47 \mathrm{kPa}$. The remaining pressure losses come from abrupt changes in the cross-sectional flow area at the entrance and exit of the flow straightener, and to the presence of a $1.6 \mathrm{~mm}$ diam resistance temperature device (RTD probe) that vertically divides the flow. A second change was to decrease the diameter of the static pressure probe $d_{\text {probe }}$ from 1.65 to $1.27 \mathrm{~mm}$ to minimize its effect on the flowfield. This change reduced the area of the throat obstructed by the probe from $3.4 \%$ to $2.0 \%$. For the SANS experiments, ${ }^{22,23}$ the pressure probe is removed from the nozzle and, thus, using a smaller probe makes the pressure trace and SANS experiments more consistent. The diameter of the holes $d_{\text {hole }}$ in the side of the static pressure probe were also changed to maintain the ratio $d_{\text {hole }} / d_{\text {probe }} \leqslant 1 / 3$ required for accurate measurement. ${ }^{25}$

For the experiments starting from $T_{0}=13.5$ and $35.0^{\circ} \mathrm{C}$, the nozzle sidewalls containing the $\mathrm{Si}$ windows were replaced. On one side, a clear polycarbonate wall let us confirm that both the static pressure and stagnation pressure probes sampled the flow in a stable manner. On the other side, an $\mathrm{Al}$ sidewall with three pressure taps let us ensure that static pressure measurements taken with the centerline probes were correct.

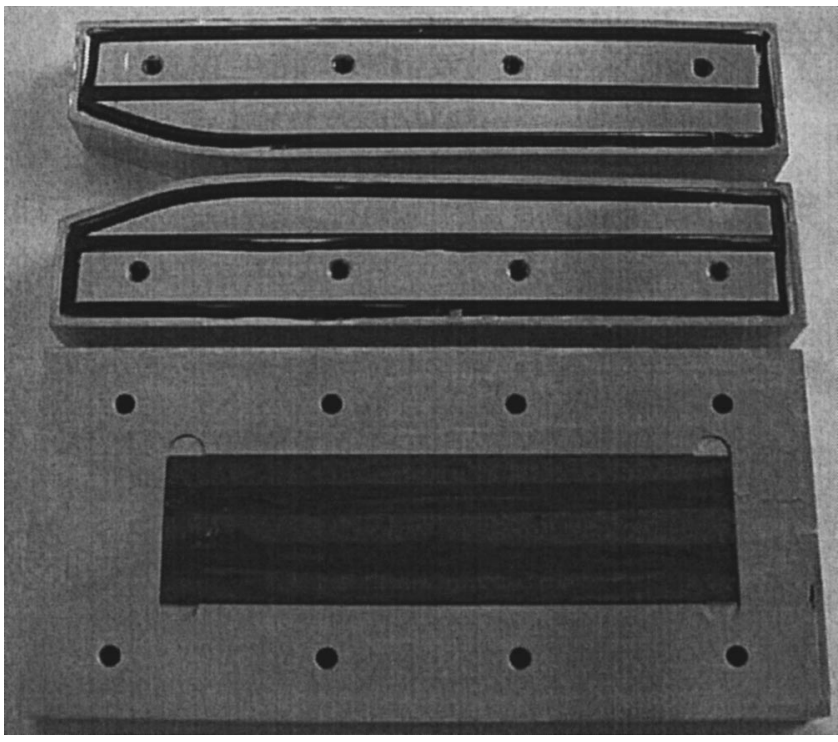

FIG. 1. (Top.) The two-dimensional Laval nozzle (nozzle A), has a total opening angle of $1.77^{\circ}$, and is displayed for flow from left to right. The central o-ring minimizes leakage between the bolt holes and the flow channel. (Bottom) The single crystal Si windows in the sidewalls are required for the small angle neutron scattering experiments. 


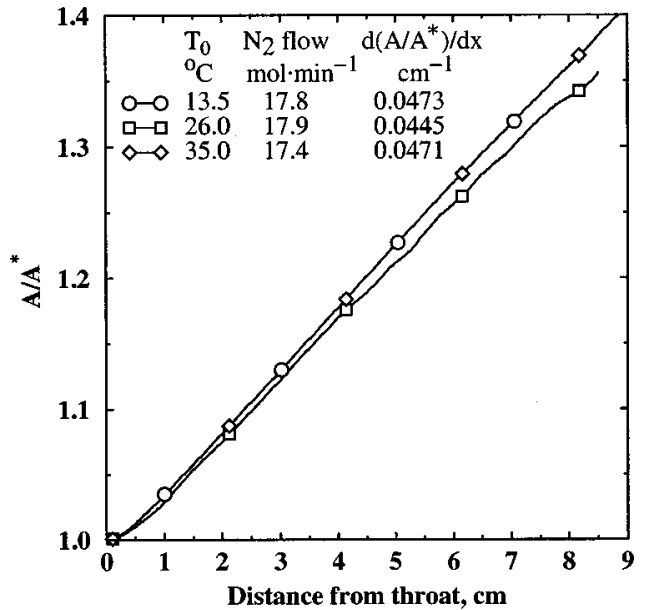

FIG. 2. The effective area ratios and the molar flowrates through the nozzle, for the three sets of condensation experiments, are compared. The nozzle was reassembled before the $T_{0}=26^{\circ} \mathrm{C}$ experiments and this changed both the expansion rates and the region over which the expansion is linear. The symbols correspond to every tenth data point.

Additional changes to the experimental apparatus had little effect on the flow. For example, in the experiments starting from $T_{0}=26.0^{\circ} \mathrm{C}$, the nozzle blocks, shown in Fig. 1 , were slightly modified by adding an extra o-ring to minimize leakage through the screw holes. For an unglued nozzle with sidewalls containing windows, typical leakage rates were $\sim 0.004 \mathrm{~mol} / \mathrm{min}$, or less than $0.03 \%$ of the total flow rate through the nozzle. This is an upper bound on the leakage rates for the $T_{0}=13.5$ and $35.0^{\circ} \mathrm{C}$ experiments where solid sidewalls were used. The leakage rates for the experiments starting from $T_{0}=26.0^{\circ} \mathrm{C}$, including the SANS ex-

TABLE I. The physical properties of $\mathrm{H}_{2} \mathrm{O}, \mathrm{D}_{2} \mathrm{O}$, and $\mathrm{N}_{2}$ required to evaluate the pressure traces. $M$ is the molecular weight (Ref. 26 for $\mathrm{N}_{2}$ ), $p_{v}$ is the equilibrium vapor pressure (Ref. 27 for $\mathrm{H}_{2} \mathrm{O}$ and Ref. 28 for $\mathrm{D}_{2} \mathrm{O}$ ), $C_{p}$ is the constant pressure heat capacity of the gas, and $C_{p l}$ is the constant pressure heat capacity for the liquid. The heats of vaporization are derived from the equilibrium vapor pressure curves using the Clausius-Clapeyron equation. Unreferenced data are from Lange. ${ }^{a}$

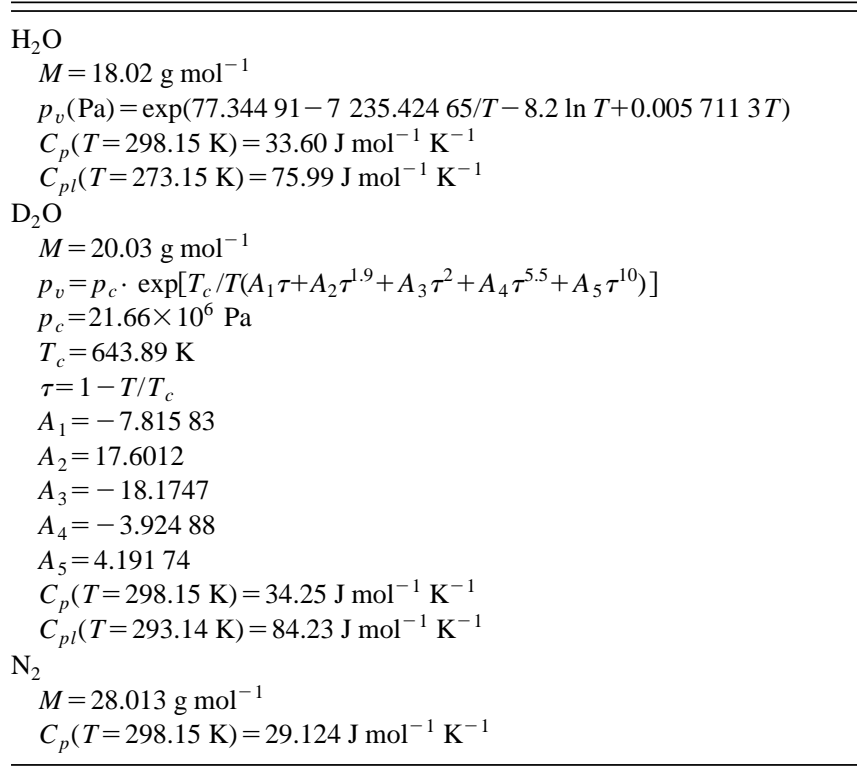

${ }^{\mathrm{a}}$ See Ref. 29.
TABLE II. $\mathrm{H}_{2} \mathrm{O}-\mathrm{D}_{2} \mathrm{O}$ onset conditions for expansions starting from a stagnation temperature of $T_{0}=13.5^{\circ} \mathrm{C}$. The stagnation pressure is $p_{0}$, the partial pressures of $\mathrm{H}_{2} \mathrm{O}$ and $\mathrm{D}_{2} \mathrm{O}$ are $p_{1}$ and $p_{2}$, respectively, $p / p_{0}$ is the expansion ratio at onset, and $T$ is the temperature at onset.

\begin{tabular}{|c|c|c|c|c|c|c|c|}
\hline \multicolumn{4}{|c|}{ Stagnation $\left(T_{0}=13.5 \pm 0.1^{\circ} \mathrm{C}\right)$} & \multicolumn{4}{|c|}{ Onset } \\
\hline$p_{0}(\mathrm{kPa})$ & $T_{0}\left({ }^{\circ} \mathrm{C}\right)$ & $p_{1}(\mathrm{~Pa})$ & $p_{2}(\mathrm{~Pa})$ & $p / p_{0}$ & $p_{1}(\mathrm{~Pa})$ & $p_{2}(\mathrm{~Pa})$ & $T(\mathrm{~K})$ \\
\hline \multicolumn{8}{|c|}{$100 \mathrm{~mol} \% \mathrm{H}_{2} \mathrm{O}$} \\
\hline 59.65 & 13.50 & 437.2 & $\cdots$ & 0.3557 & 155.5 & $\cdots$ & 213.7 \\
\hline 59.61 & 13.50 & 369.2 & $\cdots$ & 0.3406 & 125.8 & $\cdots$ & 211.1 \\
\hline 59.67 & 13.50 & 309.8 & $\cdots$ & 0.3217 & 99.7 & $\cdots$ & 207.7 \\
\hline 59.53 & 13.49 & 251.7 & $\cdots$ & 0.3038 & 76.5 & $\cdots$ & 204.3 \\
\hline 59.59 & 13.49 & 199.5 & $\cdots$ & 0.2869 & 57.2 & $\cdots$ & 201.0 \\
\hline 59.59 & 13.49 & 155.1 & $\cdots$ & 0.2642 & 41.0 & $\cdots$ & 196.4 \\
\hline 59.69 & 13.52 & 114.5 & $\cdots$ & 0.2366 & 27.1 & $\cdots$ & 190.3 \\
\hline \multicolumn{8}{|c|}{$20 \mathrm{~mol} \% \mathrm{D}_{2} \mathrm{O}$} \\
\hline 59.68 & 13.51 & 347.0 & 86.7 & 0.3625 & 125.8 & 31.4 & 214.9 \\
\hline 59.68 & 13.50 & 252.5 & 63.1 & 0.3309 & 83.6 & 20.9 & 209.4 \\
\hline 59.68 & 13.49 & 205.2 & 51.3 & 0.3077 & 63.1 & 15.8 & 205.1 \\
\hline 59.66 & 13.50 & 158.1 & 39.5 & 0.2889 & 45.7 & 11.4 & 201.4 \\
\hline 59.65 & 13.50 & 125.8 & 31.4 & 0.2676 & 33.7 & 8.4 & 197.1 \\
\hline 59.65 & 13.50 & 94.3 & 23.6 & 0.2431 & 22.9 & 5.7 & 191.8 \\
\hline \multicolumn{8}{|c|}{$40 \mathrm{~mol} \% \mathrm{D}_{2} \mathrm{O}$} \\
\hline 59.66 & 13.50 & 259.4 & 173.1 & 0.3648 & 94.6 & 63.1 & 215.3 \\
\hline 59.61 & 13.49 & 224.1 & 149.5 & 0.3514 & 78.8 & 52.5 & 213.0 \\
\hline 59.60 & 13.49 & 188.5 & 125.8 & 0.3344 & 63.1 & 42.1 & 210.0 \\
\hline 59.63 & 13.50 & 153.4 & 102.3 & 0.3135 & 48.1 & 32.1 & 206.2 \\
\hline 59.62 & 13.49 & 118.3 & 78.9 & 0.2908 & 34.4 & 22.9 & 201.8 \\
\hline 59.61 & 13.50 & 94.0 & 62.7 & 0.2737 & 25.7 & 17.2 & 198.4 \\
\hline 59.62 & 13.48 & 70.9 & 47.3 & 0.2540 & 18.0 & 12.0 & 194.2 \\
\hline \multicolumn{8}{|c|}{$60 \mathrm{~mol} \% \mathrm{D}_{2} \mathrm{O}$} \\
\hline 59.69 & 13.50 & 172.5 & 259.0 & 0.3726 & 64.3 & 96.5 & 216.6 \\
\hline 59.65 & 13.49 & 149.0 & 223.8 & 0.3592 & 53.5 & 80.4 & 214.3 \\
\hline 59.62 & 13.50 & 125.5 & 188.5 & 0.3422 & 42.9 & 64.5 & 211.4 \\
\hline 59.61 & 13.51 & 101.8 & 152.8 & 0.3197 & 32.5 & 48.9 & 207.3 \\
\hline 59.59 & 13.49 & 77.2 & 116.0 & 0.2969 & 22.9 & 34.4 & 203.0 \\
\hline 59.62 & 13.48 & 62.5 & 93.9 & 0.2784 & 17.4 & 26.1 & 199.3 \\
\hline 59.58 & 13.50 & 47.0 & 70.6 & 0.2500 & 11.7 & 17.6 & 193.3 \\
\hline \multicolumn{8}{|c|}{$80 \mathrm{~mol} \% \mathrm{D}_{2} \mathrm{O}$} \\
\hline 59.63 & 13.49 & 85 . & 343. & 0.3780 & 32.5 & 129.8 & 217.5 \\
\hline 59.63 & 13.50 & 74.3 & 296.9 & 0.3643 & 27.1 & 108.2 & 215.2 \\
\hline 59.56 & 13.50 & 62.5 & 249.7 & 0.3492 & 21.8 & 87.2 & 212.6 \\
\hline 59.68 & 13.50 & 50.7 & 202.6 & 0.3270 & 16.6 & 66.3 & 208.7 \\
\hline 59.63 & 13.49 & 39.0 & 156.2 & 0.3025 & 11.8 & 47.2 & 204.1 \\
\hline 59.60 & 13.49 & 37.7 & 151.1 & 0.3019 & 11.4 & 45.6 & 204.0 \\
\hline 59.64 & 13.49 & 33.5 & 134.3 & 0.2899 & 9.7 & 38.9 & 201.6 \\
\hline 59.47 & 13.51 & 31.1 & 124.5 & 0.2787 & 8.7 & 34.7 & 199.4 \\
\hline 59.65 & 13.49 & 29.5 & 118.4 & 0.2839 & 8.4 & 33.6 & 200.4 \\
\hline 59.65 & 13.49 & 27.3 & 109.5 & 0.2764 & 7.5 & 30.3 & 198.9 \\
\hline 59.67 & 13.49 & 25.2 & 101.1 & 0.2653 & 6.7 & 26.8 & 196.6 \\
\hline \multicolumn{8}{|c|}{$100 \mathrm{~mol} \% \mathrm{D}_{2} \mathrm{O}$} \\
\hline 59.68 & 13.50 & $\ldots$ & 427.0 & 0.3837 & $\cdots$ & 163.8 & 218.4 \\
\hline 59.67 & 13.50 & $\ldots$ & 370.5 & 0.3669 & $\cdots$ & 135.9 & 215.6 \\
\hline 59.71 & 13.49 & $\cdots$ & 311.3 & 0.3512 & $\cdots$ & 109.3 & 212.9 \\
\hline 59.67 & 13.49 & $\cdots$ & 252.2 & 0.3297 & $\cdots$ & 83.1 & 209.2 \\
\hline 59.71 & 13.49 & $\ldots$ & 193.4 & 0.3062 & $\ldots$ & 59.2 & 204.8 \\
\hline 59.60 & 13.50 & $\cdots$ & 155.4 & 0.2867 & $\cdots$ & 44.5 & 201.0 \\
\hline 59.71 & 13.50 & $\ldots$ & 116.2 & 0.2595 & $\ldots$ & 30.2 & 195.3 \\
\hline
\end{tabular}

periments, were also reduced because the nozzle was glued together. Finally, for the $26.0^{\circ} \mathrm{C}$ experiments, we used both a new flow straightener with the RTD probe shifted slightly off center to reduce contact with the pressure probe, and a new flange between the nozzle and the flow straightener that reduced the nonisentropic pressure losses to $0.33 \mathrm{kPa}$.

Although we would prefer to assemble a nozzle only 
once, during these experiments we disassembled the nozzle to clean the internal surfaces, in particular the Si windows. Unfortunately, reassembling the nozzle can change both the expansion rate and the area of the throat $A^{*}$. Figure 2 illustrates the area ratios obtained for two of the nozzle assemblies, and in the linear part of the expansion the slope changed by about $5 \%$. Small changes in $A^{*}$ are addressed by measuring the molar flow rate of nitrogen through the nozzle at fixed $p_{0}$ and $T_{0}$, and these values are included in the legend of Fig. 2. For a given gas mixture at fixed $p_{0}$, the molar flow rate through the nozzle varies inversely with the square root of the temperature, hence the molar flow rate for the $T_{0}=35^{\circ} \mathrm{C}$ calibration is lower than that for the $T_{0}$ $=13.5^{\circ} \mathrm{C}$ calibration even though the geometry is unchanged.

To determine whether the onset conditions depend systematically on the value of $T_{0}$, we conducted a final series of $\mathrm{D}_{2} \mathrm{O}$ condensation experiments using a single nozzle geometry and a probe $\left(d_{\text {probe }}=0.90 \mathrm{~mm}\right)$ that only obstructs about $1 \%$ of the nominal throat area. These probes were also supported at the exit of the nozzle by a wire mesh. The presence of this mesh influences the flow field near the nozzle exit and, thus, the final $\sim 0.5 \mathrm{~cm}$ of the nozzle was unusable for onset measurements.

\section{B. Data analysis}

The onset conditions are derived from the pressure measurements using our established onset criteria of a $0.5 \mathrm{~K}$ temperature difference between the condensing flow and an isentropic expansion of the same gas mixture. ${ }^{2}$ For the $\mathrm{H}_{2} \mathrm{O}-\mathrm{D}_{2} \mathrm{O}$ experiments, we are interested in following the phase change beyond onset and, thus, we evaluate the other flow parameters using the more rigorous treatment of the diabatic equations, i.e., Eqs. (10)-(12), and (17) of Ref. 2. The latent heat was evaluated as a function of temperature, and for the mixtures we used molar average values based on the composition of the condensible material entering the system. The physical properties ${ }^{26-29}$ used in the data evaluation program are summarized in Table I.

The supercooled vapor in the nozzle is metastable with respect to both the liquid and solid phases. We assume that the aerosol formed consists of liquid droplets because the free energy required to form a liquid interface is lower than the corresponding crystalline interface. ${ }^{30}$ Given enough time, the drops should eventually freeze, and two stage phase transitions from supercooled vapor to ice have been observed during nucleation and growth measurements of water made at similar or lower expansion rates. ${ }^{12,31}$ If, on the other hand, the temperature of the liquid droplets decreases fast enough to a low enough value, in hypersonic nozzle expansions for example, ${ }^{32}$ the diffusion of the liquid water can be slowed to the point that crystallization is suppressed and a viscous, glass-like state forms. We believe that the droplets in our nozzle experiments remain liquid because their small size and the short residence time in the nozzle $(<200 \mu$ s) reduces the probability of ice formation within the drop. If ice were to form, our values derived for the amount of material condensed would be $\sim 10 \%$ lower.

If all of the vapor entering the nozzle condensed, the average composition of the droplets would be well defined and would equal the initial vapor composition. Unfortunately, the vapor does not condense completely in any of our experiments over a wide range of $T_{0}$ and $p_{0}$. The strong chemical similarity between $\mathrm{H}_{2} \mathrm{O}$ and $\mathrm{D}_{2} \mathrm{O}$, however, makes it reasonable to treat the condensing mixture as a single compound with properties that are the molar average of the pure component values. In particular, the heats of vaporization differ by less than $7 \%$ and thus neither onset nor the final value of the condensate mass fraction $g$ are greatly affected. On the other hand, the droplet composition is most critical for interpreting the SANS data because the intensity of the scattering signal depends both on the aerosol number density and the droplet composition.

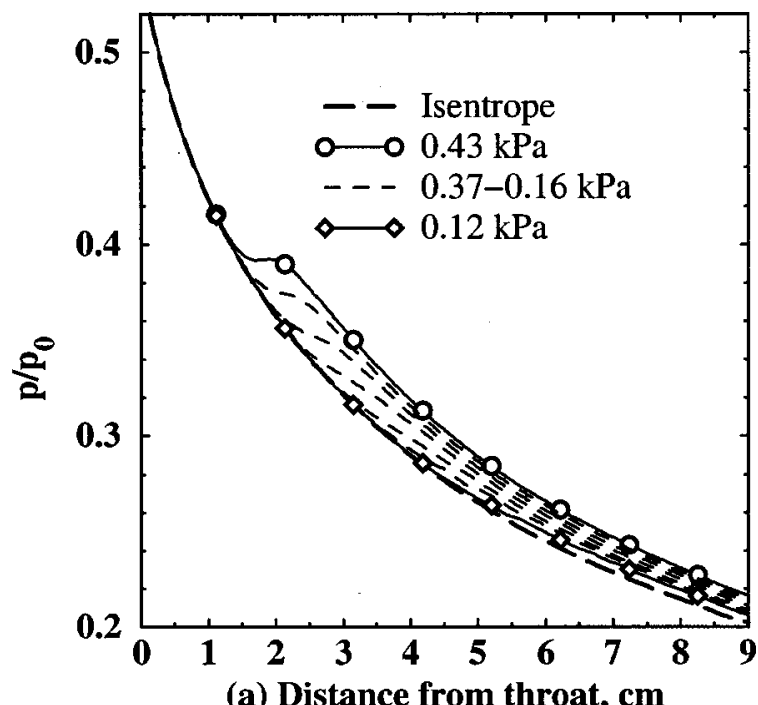

(a) Distance from throat, $\mathrm{cm}$

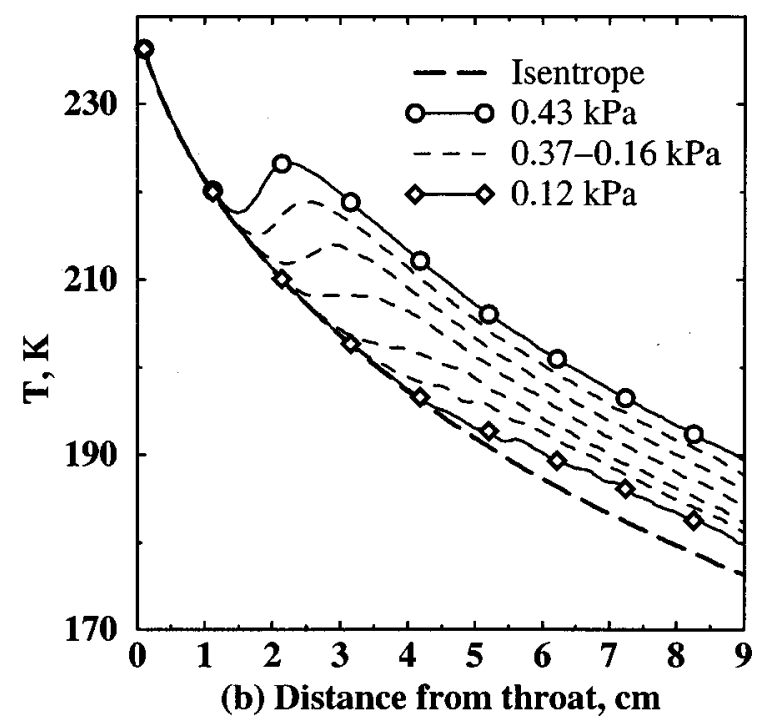

FIG. 3. (a) The measured pressure profiles normalized by the corresponding stagnation pressures (nominally $59.6 \mathrm{kPa}$ ) and (b) the derived temperature profiles for the expansion of $\mathrm{D}_{2} \mathrm{O}$ and nitrogen starting from $T_{0}=13.5^{\circ} \mathrm{C}$. The open symbols are shown for every tenth data point on the pure component curves only. 


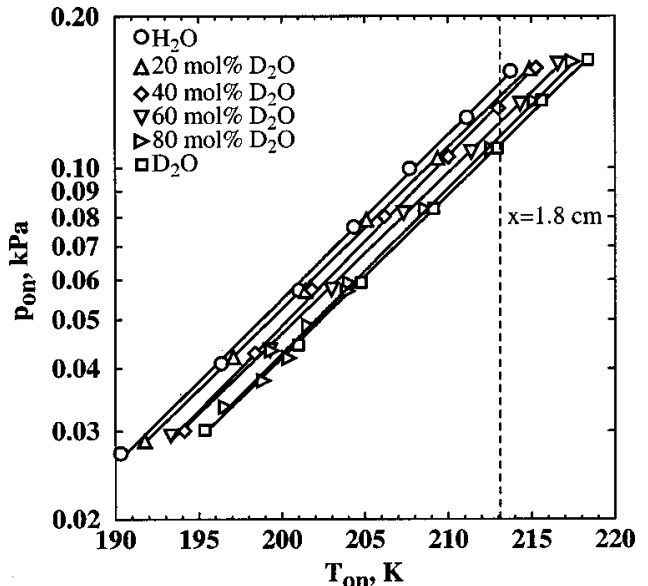

FIG. 4. The onset pressure versus onset temperature for the $\mathrm{H}_{2} \mathrm{O}-\mathrm{D}_{2} \mathrm{O}$ condensation experiments starting from $T_{0}=13.5^{\circ} \mathrm{C}$. The dashed vertical line at $213.1 \mathrm{~K}\left(-60{ }^{\circ} \mathrm{C}\right)$ corresponds to onset located $1.8 \mathrm{~cm}$ downstream of the nozzle throat. Each symbol corresponds to one pressure trace experiment.

Another issue that arises when working with $\mathrm{H}_{2} \mathrm{O}-\mathrm{D}_{2} \mathrm{O}$ mixtures is that $\mathrm{H}$ and $\mathrm{D}$ exchange rapidly in both the gas and liquid phase to form HDO. The reaction ${ }^{33,34}$

$$
\mathrm{H}_{2} \mathrm{O}+\mathrm{D}_{2} \mathrm{O} \Leftrightarrow 2 \cdot \mathrm{HDO} \text {, }
$$

has an equilibrium constant $K$ given by

$$
K=\frac{[\mathrm{HDO}]^{2}}{\left[\mathrm{H}_{2} \mathrm{O}\right]\left[\mathrm{D}_{2} \mathrm{O}\right]}=3.4-4.0 \text { at } T_{0}=25^{\circ} \mathrm{C} \text {. }
$$

All the liquid mixtures used in the condensation experiments were prepared $0.5 \mathrm{~min}$ to $48 \mathrm{~h}$ before being used, and were consumed within several hours. Thus, the mixtures should all have had time to equilibrate and in many cases HDO is an important gas phase species. If we assume that HDO has properties that are intermediate to those of $\mathrm{H}_{2} \mathrm{O}$ and $\mathrm{D}_{2} \mathrm{O}$, the final mixture will still have properties that are a molar average of those of the pure components.

\section{Materials}

The $\mathrm{D}_{2} \mathrm{O}$ used for these experiments was purchased from Sigma-Aldrich and had more than $99.9 \%$ deuterium substitution of the normal hydrogen atoms. The de-ionized $\mathrm{H}_{2} \mathrm{O}$ used for these experiments had resistivity values $>15$ $\mathrm{M} \Omega \mathrm{cm}$.

\section{RESULTS AND DISCUSSION}

The experimental results are presented in the order that they were generated. Thus, we first discuss the condensation experiments starting from $13.5^{\circ} \mathrm{C}$, followed by those starting from 35.0 and $26.0^{\circ} \mathrm{C}$, respectively. We then present an additional series of $\mathrm{D}_{2} \mathrm{O}$ experiments conducted using a single nozzle geometry and starting from the three stagnation temperatures.

\section{A. Binary experiments}

We conducted 45 condensation experiments for expansions starting from $T_{0}=13.5^{\circ} \mathrm{C}$, and Table II summarizes the initial conditions and the conditions at onset. These experiments were our first for this multicomponent system and include the lowest $\mathrm{H}_{2} \mathrm{O}-\mathrm{D}_{2} \mathrm{O}$ flows. The pressure traces for the pure $\mathrm{D}_{2} \mathrm{O}$ experiments and the corresponding temperatures are shown in Fig. 3. The results in Fig. 3 are representative of those observed for $\mathrm{H}_{2} \mathrm{O}$ and the intermediate mixtures at all values of $T_{0}$.

Figure 4 summarizes the onset values for all of the $T_{0}$ $=13.5^{\circ} \mathrm{C}$ experiments on a $\log p$ versus $T$ plot (Wilson plot). The circles correspond to the data points for pure $\mathrm{H}_{2} \mathrm{O}$, while the squares are those for pure $\mathrm{D}_{2} \mathrm{O}$. At a given onset tem-

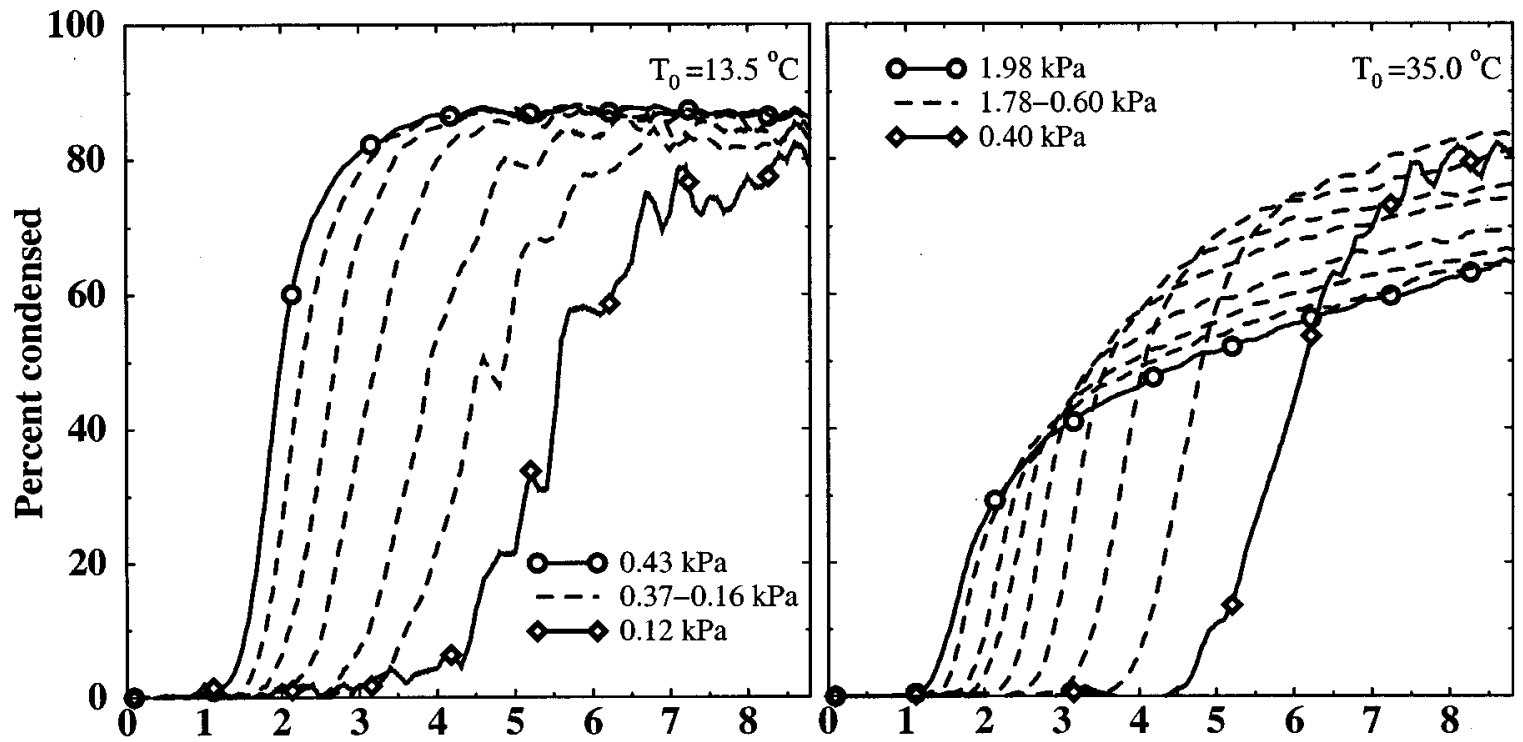

(a) Distance from throat, $\mathrm{cm}$

(b) Distance from throat, $\mathrm{cm}$

FIG. 5. The percentage of the initial $\mathrm{D}_{2} \mathrm{O}$ that condenses in the nozzle is shown as a function of position for expansions starting from: (a) $T_{0}=13.5^{\circ} \mathrm{C}$ and (b) $T_{0}=35.0^{\circ} \mathrm{C}$. The open symbols are shown for every tenth data point on the pure component curves only. Although a higher percentage of the $\mathrm{D}_{2} \mathrm{O}$ vapor entering the nozzle condenses during the $T_{0}=13.5{ }^{\circ} \mathrm{C}$ experiments, the absolute amount of condensate ( $\mathrm{kg}$ condensate $/ \mathrm{kg}$ flow) increases monotonically with the initial condensible partial pressure. 
TABLE III. $\mathrm{H}_{2} \mathrm{O}-\mathrm{D}_{2} \mathrm{O}$ onset conditions for expansions starting from a stagnation temperature of $T_{0}=35.0^{\circ} \mathrm{C}$. The stagnation pressure is $p_{0}$, the partial pressures of $\mathrm{H}_{2} \mathrm{O}$ and $\mathrm{D}_{2} \mathrm{O}$ are $p_{1}$ and $p_{2}$, respectively, $p / p_{0}$ is the expansion ratio at onset, and $T$ is the temperature at onset.

\begin{tabular}{|c|c|c|c|c|c|c|c|}
\hline \multicolumn{4}{|c|}{ Stagnation $\left(T_{0}=35.0 \pm 0.1^{\circ} \mathrm{C}\right)$} & \multicolumn{4}{|c|}{ Onset } \\
\hline$p_{0}(\mathrm{kPa})$ & $T_{0}\left({ }^{\circ} \mathrm{C}\right)$ & $p_{1}(\mathrm{~Pa})$ & $p_{2}(\mathrm{~Pa})$ & $p / p_{0}$ & $p_{1}(\mathrm{~Pa})$ & $p_{2}(\mathrm{~Pa})$ & $T(\mathrm{~K})$ \\
\hline \multicolumn{8}{|c|}{$100 \mathrm{~mol} \% \mathrm{H}_{2} \mathrm{O}$} \\
\hline 59.63 & 35.03 & 2001.3 & $\cdots$ & 0.3709 & 742.4 & $\cdots$ & 232.8 \\
\hline 59.64 & 35.03 & 1803.7 & $\cdots$ & 0.3586 & 646.8 & $\cdots$ & 230.6 \\
\hline 59.57 & 35.03 & 1602.4 & $\cdots$ & 0.3464 & 555.1 & $\cdots$ & 228.3 \\
\hline 59.64 & 35.02 & 1400.9 & $\cdots$ & 0.3340 & 467.9 & $\cdots$ & 225.9 \\
\hline 59.57 & 35.04 & 1203.0 & $\cdots$ & 0.3169 & 381.2 & $\cdots$ & 222.5 \\
\hline 59.67 & 35.02 & 1003.2 & $\cdots$ & 0.3007 & 301.7 & $\cdots$ & 219.2 \\
\hline 59.65 & 35.01 & 802.8 & $\cdots$ & 0.2837 & 227.8 & $\cdots$ & 215.5 \\
\hline 59.67 & 35.01 & 603.0 & $\cdots$ & 0.2604 & 157.1 & $\cdots$ & 210.3 \\
\hline 59.60 & 35.02 & 400.8 & $\cdots$ & 0.2376 & 95.2 & $\cdots$ & 204.9 \\
\hline 59.56 & 35.03 & 200.7 & $\cdots$ & 0.1901 & 38.2 & $\cdots$ & 192.2 \\
\hline \multicolumn{8}{|c|}{$20 \mathrm{~mol} \% \mathrm{D}_{2} \mathrm{O}$} \\
\hline 59.69 & 35.01 & 1613.9 & 403.3 & 0.3762 & 607.2 & 151.7 & 233.7 \\
\hline 59.70 & 35.01 & 1287.8 & 322.2 & 0.3571 & 459.9 & 115.1 & 230.2 \\
\hline 59.67 & 35.02 & 968.6 & 242.5 & 0.3234 & 313.3 & 78.4 & 223.8 \\
\hline 59.62 & 35.02 & 810.1 & 202.5 & 0.1907 & 154.5 & 38.6 & 192.9 \\
\hline 59.70 & 35.02 & 646.9 & 162.0 & 0.2857 & 184.8 & 46.3 & 216.0 \\
\hline 59.62 & 35.01 & 486.7 & 121.6 & 0.2657 & 129.3 & 32.3 & 211.5 \\
\hline 59.66 & 35.00 & 322.5 & 80.8 & 0.2391 & 77.1 & 19.3 & 205.2 \\
\hline \multicolumn{8}{|c|}{$40 \mathrm{~mol} \% \mathrm{D}_{2} \mathrm{O}$} \\
\hline 59.67 & 35.02 & 1220.2 & 814.1 & 0.3968 & 484.2 & 323.0 & 237.3 \\
\hline 59.65 & 35.02 & 974.5 & 649.1 & 0.3555 & 346.4 & 230.7 & 229.9 \\
\hline 59.57 & 35.02 & 732.8 & 488.7 & 0.3302 & 242.0 & 161.4 & 225.1 \\
\hline 59.66 & 35.02 & 609.0 & 405.6 & 0.3126 & 190.3 & 126.8 & 221.6 \\
\hline 59.61 & 35.02 & 488.2 & 325.7 & 0.2955 & 144.3 & 96.3 & 218.1 \\
\hline 59.65 & 35.03 & 357.3 & 238.3 & 0.2704 & 96.6 & 64.4 & 212.6 \\
\hline 59.63 & 35.02 & 243.4 & 162.1 & 0.2461 & 59.9 & 39.9 & 206.9 \\
\hline \multicolumn{8}{|c|}{$60 \mathrm{~mol} \% \mathrm{D}_{2} \mathrm{O}$} \\
\hline 59.69 & 35.03 & 816.0 & 1226.2 & 0.3865 & 315.4 & 474.0 & 235.6 \\
\hline 59.68 & 35.02 & 655.9 & 985.2 & 0.3635 & 238.5 & 358.2 & 231.4 \\
\hline 59.67 & 35.03 & 492.1 & 737.8 & 0.3353 & 165.0 & 247.4 & 226.1 \\
\hline 59.67 & 35.01 & 408.7 & 613.9 & 0.3159 & 129.1 & 193.9 & 222.3 \\
\hline 59.66 & 35.01 & 327.8 & 491.5 & 0.2989 & 98.0 & 146.9 & 218.8 \\
\hline 59.66 & 35.00 & 246.9 & 370.9 & 0.2767 & 68.3 & 102.6 & 214.0 \\
\hline 59.62 & 35.02 & 164.1 & 246.5 & 0.2529 & 41.5 & 62.3 & 208.6 \\
\hline \multicolumn{8}{|c|}{$80 \mathrm{~mol} \% \mathrm{D}_{2} \mathrm{O}$} \\
\hline 59.69 & 35.03 & 411.2 & 1645.1 & 0.3984 & 163.8 & 655.4 & 237.6 \\
\hline 59.67 & 35.02 & 330.1 & 1321.2 & 0.3722 & 122.9 & 491.8 & 233.0 \\
\hline 59.65 & 35.01 & 244.1 & 976.0 & 0.3397 & 82.9 & 331.5 & 226.9 \\
\hline 59.61 & 35.01 & 206.6 & 827.2 & 0.3233 & 66.8 & 267.4 & 223.7 \\
\hline 59.64 & 35.02 & 164.8 & 658.9 & 0.3030 & 49.9 & 199.7 & 219.6 \\
\hline 59.65 & 35.01 & 124.3 & 497.1 & 0.2819 & 35.0 & 140.1 & 215.1 \\
\hline 59.65 & 35.00 & 82.7 & 331.2 & 0.2562 & 21.2 & 84.9 & 209.3 \\
\hline \multicolumn{8}{|c|}{$100 \mathrm{~mol} \% \mathrm{D}_{2} \mathrm{O}$} \\
\hline 59.62 & 35.04 & $\cdots$ & 1982.3 & 0.3969 & $\cdots$ & 786.7 & 237.3 \\
\hline 59.53 & 35.02 & $\cdots$ & 1783.4 & 0.3852 & $\cdots$ & 686.9 & 235.3 \\
\hline 59.62 & 35.02 & $\cdots$ & 1589.1 & 0.3656 & $\cdots$ & 580.9 & 231.8 \\
\hline 59.64 & 35.02 & $\cdots$ & 1392.0 & 0.3540 & $\cdots$ & 492.8 & 229.7 \\
\hline 59.62 & 35.01 & $\cdots$ & 1184.4 & 0.3381 & $\cdots$ & 400.4 & 226.6 \\
\hline 59.59 & 35.02 & $\ldots$ & 989.6 & 0.3222 & $\ldots$ & 318.9 & 223.5 \\
\hline 59.65 & 35.01 & $\cdots$ & 795.9 & 0.3031 & $\cdots$ & 241.3 & 219.7 \\
\hline 59.63 & 35.02 & $\cdots$ & 597.9 & 0.2799 & $\cdots$ & 167.4 & 214.7 \\
\hline 59.58 & 35.02 & $\cdots$ & 401.4 & 0.2552 & $\cdots$ & 102.5 & 209.1 \\
\hline 59.61 & 35.03 & $\ldots$ & 199.9 & 0.2071 & $\cdots$ & 41.4 & 197.0 \\
\hline
\end{tabular}

perature, the higher onset pressure for $\mathrm{H}_{2} \mathrm{O}$ primarily reflects the higher equilibrium vapor pressure of $\mathrm{H}_{2} \mathrm{O}$. Because the $\mathrm{H}_{2} \mathrm{O}$ onset pressures are only about $30 \%$ higher than those for $\mathrm{D}_{2} \mathrm{O}$, individual onset data points for adjoining compo-

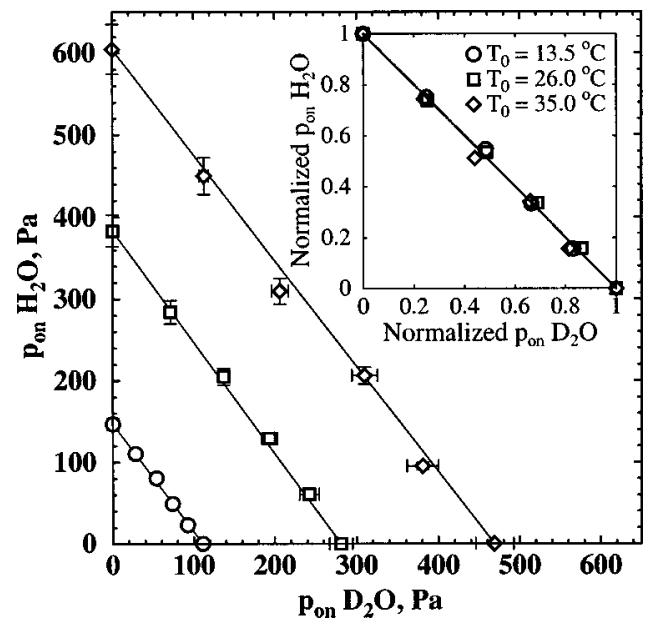

FIG. 6. The $\mathrm{H}_{2} \mathrm{O}-\mathrm{D}_{2} \mathrm{O}$ onset pressures required to maintain onset $1.8 \mathrm{~cm}$ downstream of the throat. The onset temperatures corresponding to the stagnation temperatures of $13.5,26.0$, and $35.0^{\circ} \mathrm{C}$ are $213.1,223.7$, and 229.3 $\mathrm{K}$, respectively. In the inset each curve has been normalized by the corresponding onset pressures of the pure components.

sitions occasionally overlap. Nevertheless, the data in Fig. 4 show that the onset pressures decrease uniformly as the relative $\mathrm{D}_{2} \mathrm{O}$ content of the condensible vapor increases. As in the earlier water-n-alcohol experiments, ${ }^{2}$ the onset pressures for a fixed ratio of condensible vapors are exponential functions of temperature and the fit lines are reasonably parallel. The results illustrated in Fig. 4 are representative of the Wilson plots for the experiments starting at higher $T_{0}$.

Figure 5(a) illustrates the extent of condensation observed for all of the pure $\mathrm{D}_{2} \mathrm{O}$ experiments starting from $T_{0}=13.5^{\circ} \mathrm{C}$. As the condensible pressure decreases, the phase change starts further downstream of the throat and becomes less abrupt. For the experiments starting at $T_{0}$ $=13.5^{\circ} \mathrm{C}$, roughly $87 \%$ of the initial vapor condensed for all but the lowest condensible vapor concentrations.

We conducted 48 condensation experiments starting from $T_{0}=35.0^{\circ} \mathrm{C}$, and Table III summarizes the results. Although these experiments had the highest condensible partial pressures, the inital concentration of condensible in the gas stream was always $<3.5 \mathrm{~mol} \%$ and, thus, the isentropic portion of the expansion still matched that of pure $\mathrm{N}_{2}$. In the Wilson plot (not shown) the onset pressures again decreased in a systematic and uniform manner as the condensible vapor became richer in $\mathrm{D}_{2} \mathrm{O}$. Figure 5 (b) illustrates that at these vapor concentrations, the condensation process is markedly different than that observed for the low temperature experiments. In particular, at the nozzle exit the experiments do not all reach the same degree of condensation. Instead we see that as the initial condensible vapor concentration increases, the fraction of incoming vapor that condenses systematically decreases. Indeed, at the highest partial pressure of the condensible vapor, only $\sim 60 \%$ of the incoming material condenses by the nozzle exit, and, furthermore, significant condensation is still taking place. The pure $\mathrm{D}_{2} \mathrm{O}$ results, shown in Fig. 5(b), are again representative of those for pure $\mathrm{H}_{2} \mathrm{O}$ and the mixtures. This trend makes sense physically, because in the limit of steam condensation, Moses and $\operatorname{Stein}^{7} \mathrm{ob}-$ 
TABLE IV. $\mathrm{H}_{2} \mathrm{O}-\mathrm{D}_{2} \mathrm{O}$ onset conditions for expansions starting from a stagnation temperature of $T_{0}=26.0^{\circ} \mathrm{C}$. The stagnation pressure is $p_{0}$, the partial pressures of $\mathrm{H}_{2} \mathrm{O}$ and $\mathrm{D}_{2} \mathrm{O}$ are $p_{1}$ and $p_{2}$, respectively, $p / p_{0}$ is the expansion ratio at onset, and $T$ is the temperature at onset.

\begin{tabular}{|c|c|c|c|c|c|c|c|c|c|c|c|c|c|c|c|}
\hline \multicolumn{4}{|c|}{ Stagnation $\left(T_{0}=26.0 \pm 0.1^{\circ} \mathrm{C}\right)$} & \multicolumn{4}{|c|}{ Onset } & \multicolumn{4}{|c|}{ Stagnation $\left(T_{0}=26.0 \pm 0.1^{\circ} \mathrm{C}\right)$} & \multicolumn{4}{|c|}{ Onset } \\
\hline$p_{0}(\mathrm{kPa})$ & $T_{0}\left({ }^{\circ} \mathrm{C}\right)$ & $p_{1}(\mathrm{~Pa})$ & $p_{2}(\mathrm{~Pa})$ & $p / p_{0}$ & $p_{1}(\mathrm{~Pa})$ & $p_{2}(\mathrm{~Pa})$ & $T(\mathrm{~K})$ & $p_{0}(\mathrm{kPa})$ & $T_{0}\left({ }^{\circ} \mathrm{C}\right)$ & $p_{1}(\mathrm{~Pa})$ & $p_{2}(\mathrm{~Pa})$ & $p / p_{0}$ & $p_{1}(\mathrm{~Pa})$ & $p_{2}(\mathrm{~Pa})$ & $T(\mathrm{~K})$ \\
\hline \multicolumn{8}{|c|}{$100 \mathrm{~mol} \% \mathrm{H}_{2} \mathrm{O}$} & \multicolumn{8}{|c|}{$60 \mathrm{~mol} \% \mathrm{D}_{2} \mathrm{O}$} \\
\hline 59.62 & 25.99 & 1501.3 & $\cdots$ & 0.3978 & 597.2 & $\cdots$ & 230.4 & 59.53 & 25.99 & 503.2 & 754.9 & 0.3991 & 200.8 & 301.2 & 230.6 \\
\hline 59.66 & 26.00 & 1467.7 & $\cdots$ & 0.3885 & 570.2 & $\cdots$ & 228.9 & 59.59 & 26.01 & 467.1 & 700.7 & 0.3876 & 181.1 & 271.6 & 228.7 \\
\hline 59.64 & 26.01 & 1225.9 & $\cdots$ & 0.3740 & 458.5 & $\cdots$ & 226.4 & 59.58 & 26.00 & 431.1 & 646.8 & 0.3769 & 162.5 & 243.8 & 226.9 \\
\hline 59.63 & 26.02 & 1049.4 & $\cdots$ & 0.3585 & 376.2 & $\cdots$ & 223.7 & 59.59 & 26.01 & 360.2 & 540.3 & 0.3568 & 128.5 & 192.8 & 223.3 \\
\hline 59.61 & 25.99 & 876.9 & $\cdots$ & 0.3379 & 296.3 & $\cdots$ & 219.9 & 59.65 & 26.01 & 288.0 & 432.0 & 0.3334 & 96.0 & 144.1 & 219.1 \\
\hline 59.63 & 26.00 & 701.0 & $\cdots$ & 0.3136 & 219.8 & $\cdots$ & 215.3 & 59.62 & 26.00 & 252.0 & 378.0 & 0.3197 & 80.6 & 120.9 & 216.5 \\
\hline 59.50 & 26.00 & 623.0 & $\cdots$ & 0.3075 & 191.6 & $\cdots$ & 214.1 & 59.56 & 26.00 & 215.8 & 323.8 & 0.3090 & 66.7 & 100.1 & 214.3 \\
\hline 59.55 & 26.01 & 464.8 & $\ldots$ & 0.2788 & 129.6 & $\cdots$ & 208.2 & 59.65 & & 180.3 & 270.5 & 0.2934 & 52.9 & 79.4 & 211.2 \\
\hline 59.54 & 26.01 & 409.2 & $\cdots$ & 0.2704 & 110.7 & $\cdots$ & 206.3 & 59.64 & 26.00 & 143.6 & 215.5 & 0.2700 & 38.8 & 58.2 & 206.2 \\
\hline 59.64 & 26.01 & 356.3 & $\cdots$ & 0.2606 & 92.9 & $\cdots$ & 204.2 & 59.60 & 26.00 & 122.0 & 183.0 & 0.2634 & 32.1 & 48.2 & 204.8 \\
\hline 59.59 & 26.00 & 321.5 & $\cdots$ & 0.2534 & 81.5 & $\cdots$ & 202.6 & 59.55 & 26.00 & 108.3 & 162.5 & 0.2547 & 27.6 & 41.4 & 202.8 \\
\hline 59.57 & 26.01 & 287.0 & $\cdots$ & 0.2469 & 70.8 & $\cdots$ & 201.0 & & & & & & & & \\
\hline \multicolumn{8}{|c|}{$20 \mathrm{~mol} \% \mathrm{D}_{2} \mathrm{O}$} & \multicolumn{8}{|c|}{$80 \mathrm{~mol} \% \mathrm{D}_{2} \mathrm{O}$} \\
\hline 59.65 & 26.01 & 1029.9 & 257.5 & 0.3895 & 401.1 & 100.3 & 229.0 & 59.63 & 26.02 & 250.9 & 1001.1 & 0.4068 & 102.1 & 407.2 & 231.9 \\
\hline 59.60 & 26.00 & 957.2 & 239.4 & 0.3787 & 362.5 & 90.6 & 227.2 & 59.67 & 26.02 & 241.2 & 962.4 & 0.4031 & 97.2 & 387.9 & 231.3 \\
\hline 59.62 & 26.00 & 881.1 & 220.3 & 0.3700 & 326.0 & 81.5 & 225.7 & 59.52 & 26.03 & 221.9 & 885.5 & 0.3862 & 85.7 & 342.0 & 228.5 \\
\hline 59.59 & 26.00 & 733.9 & 183.5 & 0.3519 & 258.2 & 64.6 & 222.5 & 59.55 & 26.00 & 184.8 & 737.2 & 0.3654 & 67.5 & 269.3 & 224.9 \\
\hline 59.59 & 26.00 & 590.0 & 147.5 & 0.3291 & 194.2 & 48.6 & 218.2 & 59.56 & 26.00 & 148.2 & 591.2 & 0.3441 & 51.0 & 203.4 & 221.0 \\
\hline 59.55 & 25.99 & 514.9 & 128.7 & 0.3134 & 161.4 & 40.3 & 215.2 & 59.59 & 26.00 & 129.6 & 517.0 & 0.3243 & 42.0 & 167.7 & 217.3 \\
\hline 59.53 & 26.02 & & 110.7 & 0.2999 & 132.8 & & 212.6 & 59.63 & 26.02 & 111.3 & 444.3 & 0.3145 & 35.0 & 139.7 & 215.4 \\
\hline 59.63 & 25.99 & & 92.2 & 0.2824 & 104.1 & 26.0 & 208.9 & 59.59 & 25.99 & 93.0 & 371.0 & 0.2951 & 27.4 & 109.5 & 211.5 \\
\hline 59.59 & 26.02 & 295.0 & 73.8 & 0.2685 & 79.2 & 19.8 & 205.9 & 59.65 & 26.01 & 74.0 & 295.4 & 0.2785 & 20.6 & 82.3 & 208.1 \\
\hline 59.63 & 26.00 & 251.8 & 63.0 & 0.2558 & 64.4 & 16.1 & 203.1 & 59.62 & 26.00 & 63.1 & 251.6 & 0.2672 & 16.9 & 67.2 & 205.6 \\
\hline 59.62 & 25.99 & 6.8 & 51.7 & 0.2403 & 49.7 & 12.4 & 199.5 & 59.63 & 26.00 & 52.1 & 208.1 & 0.2521 & 13.1 & 52.5 & 202.2 \\
\hline \multicolumn{8}{|c|}{$40 \mathrm{~mol} \% \mathrm{D}_{2} \mathrm{O}$} & \multicolumn{8}{|c|}{$100 \mathrm{~mol} \% \mathrm{D}_{2} \mathrm{O}$} \\
\hline 59.55 & 26.01 & 764.6 & 509.7 & 0.3904 & 298.5 & 199.0 & 229.2 & 59.61 & 26.01 & $\cdots$ & 1217.7 & 0.4081 & $\cdots$ & 497.0 & 232.1 \\
\hline 59.64 & 26.01 & 708.6 & 472.3 & 0.3834 & 271.7 & 181.1 & 228.0 & 59.64 & 26.01 & $\cdots$ & 1132.3 & 0.4042 & $\cdots$ & 457.6 & 231.4 \\
\hline 59.63 & 26.00 & 654.5 & 436.3 & 0.3750 & 245.4 & 163.6 & 226.5 & 59.61 & 26.00 & $\cdots$ & 1038.7 & 0.3891 & $\cdots$ & 404.2 & 228.9 \\
\hline 59.60 & 26.00 & 544.3 & 362.8 & 0.3523 & 191.7 & 127.8 & 222.5 & 59.57 & 26.01 & $\cdots$ & 874.4 & 0.3686 & $\cdots$ & 322.3 & 225.4 \\
\hline 59.64 & 26.01 & 436.8 & 291.1 & 0.3295 & 143.9 & & 218.3 & 59.53 & 25.99 & $\cdots$ & 782.7 & 0.3564 & $\cdots$ & 279.0 & 223.3 \\
\hline 59.61 & 26.00 & 381.7 & 254.4 & 0.3161 & 120.6 & 80.4 & 215.7 & 59.56 & 26.01 & $\ldots$ & 654.0 & 0.3381 & $\cdots$ & 221.1 & 219.9 \\
\hline 59.60 & 26.01 & 327.7 & 218.4 & 0.3053 & 100.1 & 66.7 & 213.6 & 59.62 & 26.00 & $\ldots$ & 561.7 & 0.3228 & $\cdots$ & 181.3 & 217.0 \\
\hline 59.62 & 26.02 & 272.8 & 181.8 & 0.2868 & 78.2 & 52.1 & 209.8 & 59.54 & 26.02 & $\ldots$ & 504.1 & 0.3135 & $\cdots$ & 158.1 & 215.2 \\
\hline 59.63 & 25.99 & 216.7 & 144.5 & 0.2689 & 58.3 & 38.9 & 206.0 & 59.64 & 26.01 & $\cdots$ & 411.8 & 0.2969 & $\cdots$ & 122.3 & 211.9 \\
\hline 59.54 & 26.00 & 184.5 & 123.0 & 0.2562 & 47.3 & 31.5 & 203.2 & 59.64 & 25.99 & $\cdots$ & 351.6 & 0.2790 & $\cdots$ & 98.1 & 208.2 \\
\hline \multirow[t]{4}{*}{59.53} & 26.00 & 152.7 & 101.8 & 0.2488 & 38.0 & 25.3 & 201.5 & 59.56 & 26.00 & $\cdots$ & 321.9 & 0.2708 & $\ldots$ & 87.1 & 206.4 \\
\hline & & & & & & & & 59.63 & 26.01 & $\ldots$ & 287.7 & 0.2651 & $\ldots$ & 76.3 & 205.2 \\
\hline & & & & & & & & 59.56 & 26.01 & $\cdots$ & 268.5 & 0.2584 & $\cdots$ & 69.4 & 203.7 \\
\hline & & & & & & & & 59.61 & 26.00 & $\cdots$ & 251.5 & 0.2557 & $\cdots$ & 64.3 & 203.1 \\
\hline
\end{tabular}

served that only about $5 \%$ of the steam had condensed by the exit of their nozzle.

We conducted 70 condensation experiments for expansions starting from $T_{0}=26.0^{\circ} \mathrm{C}$, and Table IV summarizes the results. Even though the nozzle geometry was slightly different for these experiments, the data are consistent with the results starting from $T_{0}=13.5$ and $35^{\circ} \mathrm{C}$.

In our nozzles, the most reliable data are those where onset is not too close to the throat or the end of the nozzle. This region corresponds roughly to that part of the nozzle where the area ratio increases linearly, and generally extends from 1.5 to $7 \mathrm{~cm}$ downstream of the throat. We therefore examined the change in onset behavior as a function of $\mathrm{H}_{2} \mathrm{O}-\mathrm{D}_{2} \mathrm{O}$ ratio in this region. In Fig. 4, the vertical dashed line at $213.1 \mathrm{~K}\left(\sim-60{ }^{\circ} \mathrm{C}\right)$ corresponds to a position in the nozzle that is $1.8 \mathrm{~cm}$ downstream of the throat. We obtained the total onset pressures at this temperature from the expo- nential fits corresponding to each of the condensible vapor compositions. We calculated the partial pressures of $\mathrm{H}_{2} \mathrm{O}$ and $\mathrm{D}_{2} \mathrm{O}$ assuming that the ratio of $\mathrm{H}_{2} \mathrm{O}: \mathrm{D}_{2} \mathrm{O}$ in the gas phase was that of the initial gas mixture. This assumption is reasonable because very little material has condensed at onset. We also determined the partial pressures of $\mathrm{H}_{2} \mathrm{O}$ and $\mathrm{D}_{2} \mathrm{O}$ corresponding to an onset $1.8 \mathrm{~cm}$ downstream of the throat for the experiments starting at the two higher stagnation temperatures. By comparing our results this way, we ensure that all of the gas mixtures experienced the same expansion rate history prior to onset.

Figure 6 illustrates that for all three values of $T_{0}$, the isothermal onset pressures for the mixtures vary linearly between those of pure $\mathrm{H}_{2} \mathrm{O}$ and pure $\mathrm{D}_{2} \mathrm{O}$, consistent with the expected ideal liquid mixture behavior. Higher values of $T_{0}$ and initial condensible pressure $p_{c 0}$ lead, of course, to correspondingly higher values of $p_{\text {on }}$ and $T_{\text {on }}$. When the onset 
TABLE V. Repeat $\mathrm{D}_{2} \mathrm{O}$ onset conditions with one nozzle assembly.

\begin{tabular}{|c|c|c|c|c|c|c|c|}
\hline \multicolumn{4}{|c|}{ Stagnation conditions } & \multicolumn{4}{|c|}{ Onset } \\
\hline$p_{0}(\mathrm{kPa})$ & $T_{0}\left({ }^{\circ} \mathrm{C}\right)$ & $p_{1}(\mathrm{~Pa})$ & $p_{2}(\mathrm{~Pa})$ & $p / p_{0}$ & $p_{1}(\mathrm{~Pa})$ & $p_{2}(\mathrm{~Pa})$ & $T(\mathrm{~K})$ \\
\hline \multicolumn{8}{|c|}{$T_{0}=13.5 \pm 0.1^{\circ} \mathrm{C}$} \\
\hline 59.68 & 13.49 & $\cdots$ & 482.2 & 0.3793 & $\cdots$ & 182.9 & 217.7 \\
\hline 59.66 & 13.50 & $\cdots$ & 344.1 & 0.3442 & $\cdots$ & 118.5 & 211.8 \\
\hline 59.66 & 13.50 & $\ldots$ & 389.3 & 0.3554 & $\cdots$ & 138.3 & 213.7 \\
\hline 59.63 & 13.50 & $\cdots$ & 229.7 & 0.3054 & $\cdots$ & 70.1 & 204.6 \\
\hline 59.66 & 13.49 & $\cdots$ & 137.7 & 0.2627 & $\cdots$ & 36.2 & 196.0 \\
\hline 59.66 & 13.49 & $\cdots$ & 182.9 & 0.2868 & $\cdots$ & 52.4 & 201.0 \\
\hline \multicolumn{8}{|c|}{$T_{0}=26.0 \pm 0.1^{\circ} \mathrm{C}$} \\
\hline 59.67 & 26.01 & $\cdots$ & 1080.5 & 0.3957 & $\cdots$ & 427.5 & 230.0 \\
\hline 59.68 & 26.01 & $\cdots$ & 1077.2 & 0.3919 & $\cdots$ & 422.2 & 229.4 \\
\hline 59.69 & 26.01 & $\cdots$ & 1047.4 & 0.3897 & $\cdots$ & 408.1 & 229.0 \\
\hline 59.69 & 26.00 & $\cdots$ & 738.3 & 0.3565 & $\cdots$ & 263.2 & 223.3 \\
\hline 59.69 & 25.99 & $\cdots$ & 539.6 & 0.3291 & $\cdots$ & 177.6 & 218.2 \\
\hline 59.69 & 26.00 & $\cdots$ & 312.4 & 0.2862 & $\cdots$ & 89.4 & 209.7 \\
\hline 59.67 & 26.00 & $\cdots$ & 230.0 & 0.2528 & $\cdots$ & 58.1 & 202.4 \\
\hline \multicolumn{8}{|c|}{ Insulated $T_{0}=35.0 \pm 0.1^{\circ} \mathrm{C}$} \\
\hline 59.74 & 35.01 & $\cdots$ & 1454.3 & 0.3877 & $\cdots$ & 563.8 & 235.6 \\
\hline 59.65 & 35.02 & $\cdots$ & 1213.0 & 0.3612 & $\cdots$ & 438.1 & 230.9 \\
\hline 59.80 & 35.00 & $\cdots$ & 973.7 & 0.3463 & $\cdots$ & 337.2 & 228.1 \\
\hline 59.75 & 35.00 & $\cdots$ & 726.0 & 0.3226 & $\cdots$ & 234.2 & 223.5 \\
\hline 59.69 & 35.00 & $\cdots$ & 484.9 & 0.2856 & $\cdots$ & 138.5 & 215.9 \\
\hline 59.73 & 35.01 & $\cdots$ & 243.8 & 0.2305 & $\cdots$ & 56.2 & 203.1 \\
\hline \multicolumn{8}{|c|}{$T_{0}=35.0 \pm 0.1^{\circ} \mathrm{C}^{3}$} \\
\hline 59.66 & 35.00 & $\cdots$ & 1252.7 & 0.3579 & $\cdots$ & 448.4 & 230.3 \\
\hline 59.69 & 35.02 & $\cdots$ & 569.4 & 0.2886 & $\cdots$ & 164.3 & 216.6 \\
\hline
\end{tabular}

pressure curves in Fig. 6 are normalized with respect to the pure $\mathrm{H}_{2} \mathrm{O}$ and $\mathrm{D}_{2} \mathrm{O}$ pressures, as shown in the inset of Fig. 6, the three curves collapse onto one. There is a small amount of scatter around the dashed line connecting the normalized pure $\mathrm{H}_{2} \mathrm{O}$ and $\mathrm{D}_{2} \mathrm{O}$ pressures, due to experimental error, but ideal behavior is clearly indicated for the mixtures. The error bars are derived by assuming a $1 \mathrm{~K}$ uncertainty in the value of $T_{0}$ and a $5 \%$ uncertainty in $p_{\text {on }}$.

\section{B. Experiment uncertainty}

Because the binary condensation experiments described above were completed using two different nozzle assemblies, we conducted an additional set of $\mathrm{D}_{2} \mathrm{O}$ experiments starting

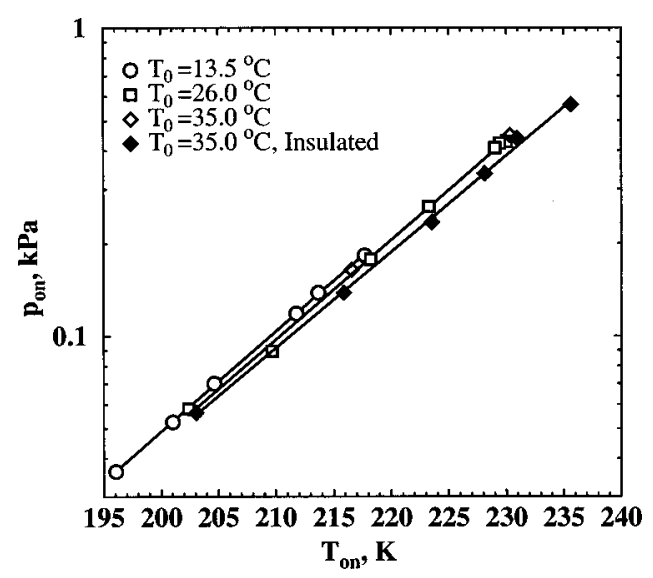

FIG. 7. Some of the variability in the $\mathrm{D}_{2} \mathrm{O}$ onset pressures measured using a single nozzle assembly may depend on the degree of insulation on the system.

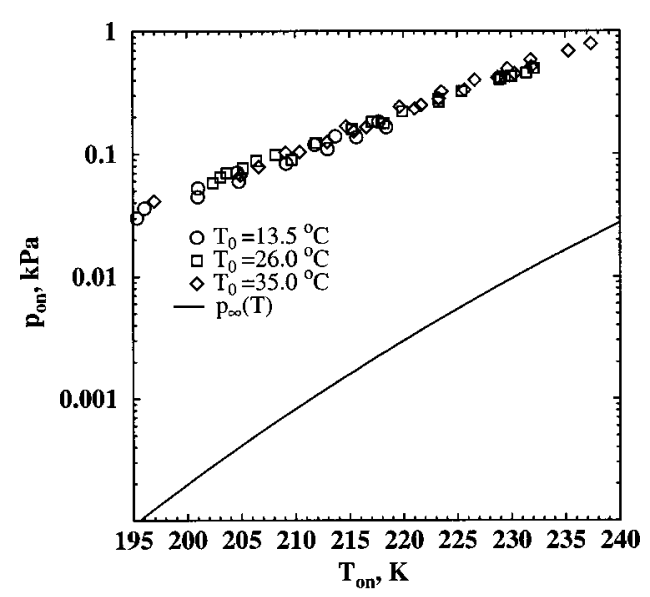

FIG. 8. The $\mathrm{D}_{2} \mathrm{O}$ onset measurements are compared to the equilibrium vapor pressure curve (see Ref. 28). On this scale the data overlap quite well.

from the three different stagnation temperatures but using a single nozzle assembly. These results are summarized in Table $\mathrm{V}$ and include two $T_{0}=35.0^{\circ} \mathrm{C}$ experiments from Dieregsweiler. ${ }^{3}$

Figure 7 illustrates the $\mathrm{D}_{2} \mathrm{O}$ onset pressure curves for these experiments. The curves almost coincide with only a small decrease in the onset pressure for a given onset temperature as $T_{0}$ is increased. Alternatively, at a fixed onset pressure, for example $p_{\text {on }}=0.1 \mathrm{kPa}$, there is $1-2 \mathrm{~K}$ difference in the onset temperature for experiments that start from $13.5^{\circ} \mathrm{C}$ and those that start from 26 or $35^{\circ} \mathrm{C}$. In contrast, the $\mathrm{D}_{2} \mathrm{O}$ data in Tables II-IV show the opposite trend, i.e., at a fixed onset pressure the onset line for the $13.5^{\circ} \mathrm{C}$ data lies about $\sim 1-2 \mathrm{~K}$ to the right of the $35^{\circ} \mathrm{C}$ data. Our concern is that our measurements contain a systematic bias, primarily associated with the position of the RTD probe, and that the measured temperatures were influenced by the ambient room temperature.

We therefore insulated the flow straightener and the portion of the RTD probe exposed to ambient conditions and repeated the $35^{\circ} \mathrm{C}$ experiments because these are the furthest from room temperature. The shift between the insulated and

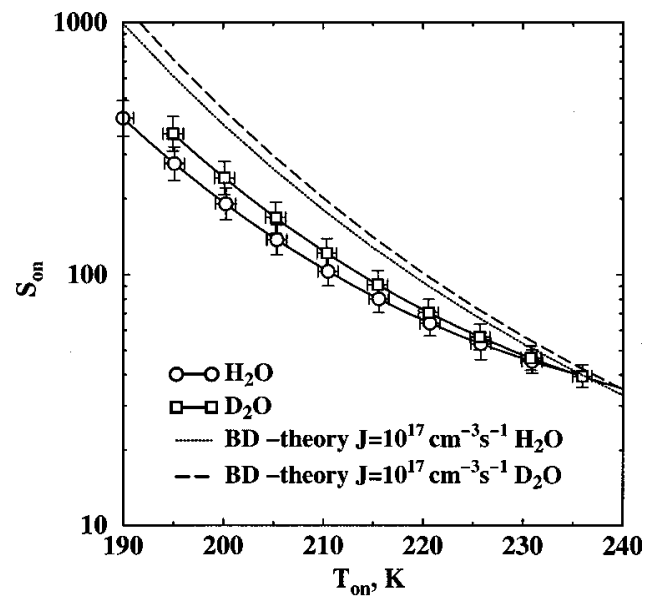

FIG. 9. The supersaturation at onset for $\mathrm{D}_{2} \mathrm{O}$ and $\mathrm{H}_{2} \mathrm{O}$ increase rapidly as $T_{\text {on }}$ decreases. The experimental trend is consistent with the predictions of classical nucleation theory. 
uninsulated $T_{0}=35.0^{\circ} \mathrm{C}$ data suggest that the temperature measured by the RTD probe reflects both the temperature of the gas entering the nozzle, as well as the temperature of the flow straightener walls and the exposed portion of the probe. The latter approaches room temperature. To obtain a reading of $T_{0}=35.0^{\circ} \mathrm{C}$, the gas may have been slightly overheated in the uninsulated experiments and, thus, condensation was shifted slightly downstream to lower temperatures. The degree of overheating for the uninsulated experiments is, however, constrained by the bath temperature and this was $<2{ }^{\circ} \mathrm{C}$ warmer than that of the insulated experiments. Since room temperature is $\approx 20^{\circ} \mathrm{C}$, this effect is less important for the $T_{0}=26.0$ and $13.5^{\circ} \mathrm{C}$ data.

Ideally, the whole system should be in a temperature controlled environment with the ambient temperature close to the stagnation temperature. Currently, the parts of the experimental system containing vapor are insulated. The suspected bias in temperature measurement does not alter the interpretation of the binary data taken at a fixed stagnation temperature. It only changes the temperature difference between the three series of experiments, and even this uncertainty is constrained by the measured values of $T_{0}$ and the corresponding water bath temperature. Although we believe this bias exists, we have not corrected the data in Tables II-IV.

\section{Critical supersaturation curves for $\mathrm{D}_{2} \mathrm{O}$ and $\mathrm{H}_{2} \mathrm{O}$}

Figure 8 presents all of the pure $\mathrm{D}_{2} \mathrm{O}$ onset pressures and compares them to the equilibrium vapor pressure. On this scale, the data are consistent and define the limit to which $\mathrm{D}_{2} \mathrm{O}$ vapor can be supersaturated before condensation occurs in our nozzle. The $\mathrm{H}_{2} \mathrm{O}$ data in Tables II-IV define a similar sharp curve, and these data in turn agree with our previously published water measurements.

Homogeneous nucleation is a strong function of both supersaturation and temperature. To examine how the supersaturation at onset varies with $T_{\text {on }}$, we fit all of the onset pressure data for pure $\mathrm{D}_{2} \mathrm{O}$, shown in Fig. 8, to an exponential function of onset temperature and divided this function by the equilibrium vapor pressure. We treated the $\mathrm{H}_{2} \mathrm{O}$ onset values presented in Tables II-IV in the same way. Figure 9 shows that the supersaturation at onset for both species increases rapidly with decreasing temperature reaching nearly 400 at the lowest values of $T_{\text {on }}$. Although the Wilson plots all show that the onset pressures for $\mathrm{H}_{2} \mathrm{O}$ lie above those for $\mathrm{D}_{2} \mathrm{O}$, once $p_{\text {on }}$ is normalized by the equilibrium vapor pressure at $T_{\text {on }}$ the supersaturation at onset for $\mathrm{H}_{2} \mathrm{O}$ is lower than for $\mathrm{D}_{2} \mathrm{O}$ over most of our temperature range. Only as $T_{\text {on }}$ approaches $235-240 \mathrm{~K}$ do the two curves merge. We note that at these higher temperatures, Wölk and Strey ${ }^{14}$ found no difference in the measured nucleation rate between $\mathrm{D}_{2} \mathrm{O}$ and $\mathrm{H}_{2} \mathrm{O}$ when they plotted their results in terms of supersaturation rather than pressure.

Also included in Fig. 8 are lines corresponding to a nucleation rate $J_{\mathrm{BD}}=10^{17} \mathrm{~cm}^{-3} \mathrm{~s}^{-1}$ calculated using the Becker-Döring nucleation rate expression. ${ }^{35}$ This value of $J$ is close to the peak nucleation rate predicted by a model for nucleation and droplet growth in the nozzle, when the nucle- ation rate has been adjusted to match the onset of condensation. ${ }^{23}$ At high temperatures the theoretical lines agree quite well with the measured onset values. Furthermore, as the temperature decreases, the theoretical curves separate from each other in a manner similar to the experimental curves. Finally, the rapid deviation of the theoretical curves from the experimental ones simply confirms that the temperature dependence of the classical nucleation theory is too strong, an effect that we discuss in more detail in a separate paper. ${ }^{36}$

\section{SUMMARY AND CONCLUSIONS}

We investigated the condensation of $\mathrm{H}_{2} \mathrm{O}, \mathrm{D}_{2} \mathrm{O}$, and four intermediate mixtures starting from three stagnation temperatures. In this highly ideal system, the onset pressure at constant onset temperature varies linearly between the values for the pure components. The linear relationship is even more pronounced than in the earlier binary measurements made with ethanol-propanol mixtures. ${ }^{2}$

We also pooled the onset measurements for all of the pure species experiments to determine the supersaturation reached by $\mathrm{H}_{2} \mathrm{O}$ and $\mathrm{D}_{2} \mathrm{O}$ at onset. At high temperatures, $\sim 240 \mathrm{~K}$, the onset saturations are indistinguishable, but as the temperature decreases $\mathrm{D}_{2} \mathrm{O}$ appears to reach higher supersaturations than $\mathrm{H}_{2} \mathrm{O}$. This behavior is in agreement with the predictions of the classical nucleation theory.

\section{ACKNOWLEDGMENTS}

This work was supported by the National Science Foundation, under Grants Nos. CHE-0097896, CHE-0089136, INT-0089897, and by the Donors of the Petroleum Research Fund administered by the American Chemical Society. We thank Uta Dieregsweiler and Amjad Khan for their assistance in completing the final $\mathrm{D}_{2} \mathrm{O}$ experiments.

${ }^{1}$ R. Strey, Y. Viisanen, and P. E. Wagner, J. Chem. Phys. 103, 4333 (1995).

${ }^{2}$ B. E. Wyslouzil, C. H. Heath, G. Wilemski, and J. L. Cheung, J. Chem. Phys. 113, 7317 (2000).

${ }^{3}$ U. M. Dieregsweiler, M. S. thesis, Worcester Polytechnic Institute, Worcester, MA, 2001.

${ }^{4}$ K. Oswatitsch, Z. Angew. Math. Mech. 22, 1 (1942).

${ }^{5}$ H. L. Jaeger, E. J. Willson, and P. G. Hill, J. Chem. Phys. 51, 5380 (1969).

${ }^{6}$ B. J. C. Wu, P. P. Wegener, and G. D. Stein, J. Chem. Phys. 68, 308 (1978).

${ }^{7}$ C. A. Moses and G. D. Stein, J. Fluids Eng. 100, 311 (1978).

${ }^{8}$ D. Barschdorff, Phys. Fluids 18, 529 (1975).

${ }^{9}$ G. D. Stein and P. P. Wegener, J. Chem. Phys. 46, 3685 (1967).

${ }^{10}$ R. Miller, R. J. Anderson, J. L. Kassner, and D. E. Hagen, J. Chem. Phys. 78, 3204 (1983).

${ }^{11}$ P. E. Wagner and R. Strey, J. Phys. Chem. 85, 2694 (1981).

${ }^{12}$ Y. Viisanen, R. Strey, and H. Reiss, J. Chem. Phys. 99, 4680 (1993).

${ }^{13}$ Y. Viisanen, R. Strey, and H. Reiss, J. Chem. Phys. 112, 8205 (2000).

${ }^{14}$ J. Wölk and R. Strey, J. Phys. Chem. B 105, 11683 (2001).

${ }^{15}$ F. Peters and B. Paikert, Exp. Fluids 7, 7748 (1989).

${ }^{16}$ C. C. M. Luijten, K. J. Bosschaart, and M. E. H. van Dongen, J. Chem. Phys. 106, 8116 (1997).

${ }^{17}$ R. Heist and H. Reiss, J. Chem. Phys. 59, 865 (1973).

${ }^{18}$ H. Flood and L. Tronstad, Z. Phys. Chem. Abt. A 175, 347 (1936).

${ }^{19}$ C. F. Lee, in Condensation in High Speed Flows, edited by A. A. Pouring (American Society of Mechanical Engineers, New York, 1977), pp. 8396.

${ }^{20}$ B. E. Wyslouzil, J. L. Cheung, G. Wilemski, and R. Strey, Phys. Rev. Lett. 79, 431 (1997). 
${ }^{21}$ B. E. Wyslouzil, J. L. Cheung, G. Wilemski, R. Strey, and J. Barker, Phys. Rev. E 60, 4330 (1999).

${ }^{22}$ C. H. Heath, K. Streletzky, J. Wölk, B. E. Wyslouzil, and R. Strey, in Nucleation and Atmospheric Aerosols 2000: 15th International Conference, edited by B. N. Hale and M. Kulmula (American Institute of Physics, Melville, NY, 2000), pp. 59-62.

${ }^{23}$ C. H. Heath, K. Streletzky, B. E. Wyslouzil, and G. Wilemski, in Nucleation and Atmospheric Aerosols 2000: 15th International Conference, edited by B. N. Hale and M. Kulmula (American Institute of Physics, Melville, NY, 2000), pp. 63-66.

${ }^{24}$ G. Wilemski, Phys. Rev. E 61, 557 (2000).

${ }^{25}$ G. D. Stein, Ph.D. thesis, Yale University, New Haven, CT, 1967.

${ }^{26}$ W. M. Chase, Jr. et al., JANAF Thermochemical Tables, 3rd ed. (American Chemical Society, Washington DC, 1985).
${ }^{27}$ P. E. Wagner, Aerosol Research III (University of Vienna, Vienna, Austria, 1981), p. 209

${ }^{28}$ P. G. Hill and R. D. C. MacMillan, J. Phys. Chem. Ref. Data 9, 735 (1980).

${ }^{29}$ Lange's Handbook of Chemistry, 14th ed., edited by J. A. Dean (McGraw-Hill, New York, 1992).

${ }^{30}$ C. A. Knight, The Freezing of Supercooled Liquids (Van Nostrand, Princeton, NJ, 1967).

${ }^{31}$ J. Huang and L. S. Bartell, J. Phys. Chem. 99, 3924 (1995).

${ }^{32}$ L. S. Bartell and R. A. Machonkin, J. Phys. Chem. 94, 6468 (1990).

${ }^{33}$ H.-C. Chang, K.-H. Huang, Y.-L. Yeh, and S. H. Lin, Chem. Phys. Lett. 326, 93 (2000).

${ }^{34}$ F. Libnau, A. Christy, and O. Kvalheim, Appl. Spectrosc. 49, 1431 (1995).

${ }^{35}$ R. Becker and W. Döring, Ann. Phys. (Paris) 24, 719 (1935).

${ }^{36}$ J. Wölk, R. Strey, C. H. Heath, and B. E. Wyslouzil, J. Chem. Phys. 117, 4954 (2002) 